\title{
SPECIAL SECTION
}

\section{Civil Engineering - Ongoing Technical Research. Part I}

\author{
L. CZARNECKI and D. VAN GEMERT
}

The mission of the Bulletin of the Polish Academy of Sciences: Technical Sciences is to create "an indispensable forum for the exchange of knowledge and experience between professionals from both academic and industrial environments". Particularly in civil engineering the inter-penetration of science and technology is deeply advanced and simultaneously very important. Two preceding special sections on civil engineering were published in 2013 [1] and 2015 [2]. This special section on "Civil Engineering - Ongoing Technical Research" has been prepared in light of the $70^{\text {th }}$ anniversary of the Building Research Institute (ITB) in Warsaw. The beginnings of institutes of this kind, devoted to research in properties of construction materials used in mechanical structures and construction industry, date back to the mid- $19^{\text {th }}$ century. They were established at universities of technology. One should note the locations and dates of establishment of first of such research units at certain universities of technologies: Munich - 1870, Berlin - 1871, Vienne - 1873, Zurich - 1880, Lviv - 1884, Warsaw - 1918. Until 1939, the leading building research institute in Poland was the Road Research Institute of Warsaw University of Technology. The seminar accompanying the anniversary of ITB, entitled "The Strategy of Construction Research Institutes", presented a compendium of knowledge and strategy of building institutes that co-shape the European construction space. The regulations of ITB stated that the Building Research Institute was established to conduct comprehensive research in order to improve and increase production of construction and road materials, as well as to improve construction technology using all scientific advances. Of course, to create trends in the discipline development is not the task or mission of ITB only.

In this context, the word "ongoing" in the Section title has been treated both literally and figuratively. All current waiting papers from the editorial civil engineering portfolio have been included into the Special Section. The papers which are presently in the editorial process will be published in the Special Section Part II. In such case we have not only obtained a cross-section of the present publishing activity, but also the characteristic picture of the civil engineering in a flash. Although very randomly created, this picture is a surprisingly comprehensive one.

Civil engineering as a discipline of applied science is always seeking for its place on the map of knowledge. Each of the papers included in this Special Section consists of two components: science and engineering balanced in various ways. One of the dilemmas of the civil engineering is the following contro- versy: the requirement of durability (over 50 years) versus the risk of progress. We need to ensure that construction elements meet the requirements not only at the time of testing, but also that they will be good enough after tens of years of service life. The nature of an applied science involves the problem of equilibrium between simplicity and accuracy. The "breaking even" in the meaning of probably approximately correct model and value. The risk of estimation error, even a small one, could cause in consequence a catastrophic result.

All these problems are discussed in the invited paper opening the section, entitled: "Scientific basis and rules of thumb in civil engineering: Conflict or harmony?", examining the meaning and justification of "the rules of thumb" [3] in the construction field, in which science and engineering are so intermingled. Shortly speaking, how much "it is better to be roughly right than precisely wrong" (J. M. Keyness). All the other papers in the Section illustrate those problems in various but very obvious ways. The topics of the papers could be assigned under the headlines that follow.

1. Risk of performance evaluation - the influence of the uncertainty in the assessment of materials properties tested in laboratories [4] and on-site [5]. The uncertainty of the assessment as a research challenge is considered by E. Szewczak and A. Piekarczuk [4]. This is a study of various combinations of uncertainties during the evaluation process and their potential impact on the big differences in assessment accuracy. The fundamental question: to what extent is the assessment of a product based on tests reliable?, will be since now more easy to answer. A similar problem - but in a more formalized way - is addressed by L. Brunarski and M. Dohojda [5] on the evaluation of the most fundamental construction feature: the compressive strength of concrete in situ (in existing structure).

2. Particular problems of the building performance: sustainability [6], fire threat [7, 8] and frost durability [9]. R. Geryło [6] presents conditioning for sustainable building relevant to energy consuming. In the context of sustainability, energy related conditions constitute a new set of indicators for identifying the performance and efficiency of building construction technologies. Two further papers entitled "Combustibility of building products versus fire safety" (J. Fangrat) [7] and "The philosophy of fire safety engineering in the shaping of civil engineering development" 
(W. Węgrzyński, P. Sulik) [8] illustrate a dynamically developing sub-discipline - fire safety engineering. How fire safety requirements shape the development of civil engineering has been considered and documented. The frost resistance is one of the basic attributes of concrete durability. This problem is discussed by J. Wawrzeńczyk et al. [9], focusing on the concrete with granulated blast furnace slag. The subject of the study is more sustainable - eco-friendly concrete. The innovative interpretation of the equivalent performance concept has also been presented in the paper.

\section{Examples of the analytical [10] and numerical [11] models} seeking for the technological [11] and construction [10] solution. In particular, the aims of the studies find a theoretical basis for some engineering quests: dynamic stability of the selected construction elements (P. Obara, W. Gilewski) [10] and structure-subsoil interaction of multiple-layer pavement structure system (M. Kadela) [11]. These are examples of the search for particular models: how to predict the response of an engineering structure to the given loads throughout its service life.

\section{Seeking for new materials solutions by better under-} standing of the nature of materials [12], material composition modification [13] and the use of relatively new mechanism of creating synergy by chemical interaction between organic and nonorganic components [14]. T. Tracz considers porosity of cement-pastes versus their gas permeability. It presents an interesting illustration of the relation between microstructure and engineering features [12]. M. Iwański et al. present [13] an eco-friendly solution of asphalt paving. The new solution is the result of material modification, but also an innovative change in technology. The results are presented on the response surface and in the form of desirability functions, which brings to us the advantage of generalization. The last paper in this Section by W. Ru, J. Li, T. Zhang and L. Czarnecki, entitled "Chemical interaction between polymer and cement in polymer-cement concrete", expresses the conviction that organic-inorganic chemically bound composites will open the gate to the development of new generations of highly performing concretes [14].

The papers in this issue show that civil engineering has dramatically evolved during the past 70 years. The construction execution methods have been optimized and became much more labour-friendly thanks to the introduction of developments in mechanical and electro-mechanical engineering. Furthermore, building materials science evolved dramatically by embracing physics and chemistry as fundamental construction sciences. This approach enables increasingly thorough understanding of material structure and performance, descending from the macro to the micro and nowadays already to the nano level. Designing materials according to the desired performance will certainly be possible in the near future. The authors of this editorial are convinced that the evolution of building materials science and construction techniques has brought civil engineering at the doorstep of a spectacular breakthrough to sustainability!
Acknowledgements. We would like to express our appreciation to the authors of papers included in this Special Section, which present research results obtained by eight research centres. We would also like to thank all reviewers for their efforts and valuable input which contributed significantly to improving the quality of papers. Very special acknowledgments are addressed to Prof. Tadeusz Kaczorek, Editor-in-Chief, and all members of the Editorial Board for giving Guest Editors the opportunity to present this Special Section. Finally, we would like to thank Ms. Anna Jurkiewicz, Copy Editor, for her professional assistance. We dare to express the hope that this Special Section will be of interest to the readers, showing them the fundamental evolution that took place in building materials science during the past 70 years.

Employees and scientists of the Building Research Institute ITB are happy and proud to be able to contribute to the development of more sustainable construction and to a more sustainable built environment.

\section{REFERENCES}

[1] L. Czarnecki and W. Radomski, "Special Section on Civil Engineering”, Bull. Pol. Ac.: Tech. 61 (1), 3-4 (2013).

[2] L. Czarnecki and W. Trąmpczyński, "Special Section on Diagnostics and Durability Estimation of Civil Structures", Bull. Pol. Ac.: Tech. 63 (1), 3-5 (2015).

[3] L. Czarnecki and D. Van Gemert, "Scientific basis and rules of thumb in civil engineering: Conflict or harmony?, Bull. Pol. Ac.: Tech. 64 (4), 665-673 (2016).

[4] E. Szewczak and A. Piekarczuk, "Performance evaluation of the construction products as a research challenge. Small error - big difference in assessment?", Bull. Pol. Ac.: Tech. 64 (4), 675-686 (2016).

[5] L. Brunarski and M. Dohojda, "An approach to in-situ compressive strength of concrete", Bull. Pol. Ac.: Tech. 64 (4), 687-695 (2016).

[6] R. Geryło, "Energy-related conditions and envelope properties for sustainable buildings", Bull. Pol. Ac.: Tech. 64 (4), 697-707 (2016).

[7] J. Fangrat, "Combustibility of building products versus fire safety”. Bull. Pol. Ac.: Tech. 64 (4), 709-717 (2016).

[8] W. Węgrzyński and P. Sulik, "The philosophy of fire safety engineering in the shaping of civil engineering development", Bull. Pol. Ac.: Tech. 64 (4), 719-730 (2016).

[9] J. Wawrzeńczyk, T. Juszczak and A. Molendowska, "Determining equivalent performance for frost durability of concrete containing different amounts of ground granulated blast furnace slag", Bull. Pol. Ac.: Tech. 64 (4), 731-737 (2016).

[10] P. Obara and W. Gilewski, "Dynamic stability of moderately thick beams and frames with the use of harmonic balance and perturbation methods", Bull. Pol. Ac.: Tech. 64 (4), 739-750 (2016).

[11] M. Kadela, "Model of multiple-layer pavement structure-subsoil", Bull. Pol. Ac.: Tech. 64 (4), 751-762 (2016).

[12] M. Iwański, P. Buczyński and G. Mazurek, "The use of gabbro dust in the cold recycling of asphalt paving mixes with foamed bitumen", Bull. Pol. Ac.: Tech. 64 (4), 763-773 (2016).

[13] T. Tracz, "Open porosity of cement pastes and their gas permeability", Bull. Pol. Ac.: Tech. 64 (4), 775-783 (2016).

[14] W. Ru, L. Jian, Z. Tao and L. Czarnecki, "Chemical interaction between polymer and cement in polymer-cement concrete", Bull. Pol. Ac.: Tech. 64 (4), 785-792 (2016). 


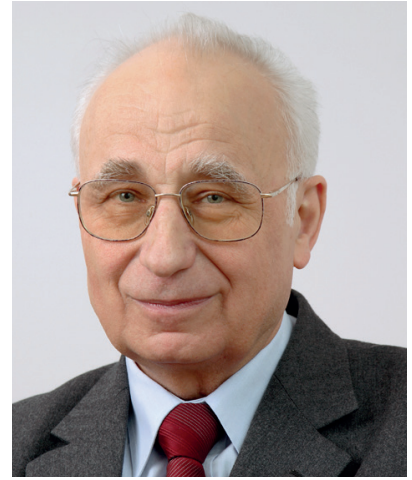

Lech Czarnecki PhD, D.Sc. - Scientific Secretary of Building Research Institute at Warsaw, Poland. He was Vice-President (2001-2006) and President (2006-2013) of International Congress on Polymers in Concrete (ICPIC). He is member of Board of Directors of ICPIC since 1992 until now. He is senior member of RILEM since 1992. He was Head of the Building Materials Engineering Department of Warsaw University of Technology (1972-2011) and Vice-Rector for Academic Affairs (2000-2006). He was awarded as an outstanding reviewer for Elsevier Journal in 2014. He was also awarded prizes "for eminent activities in new frontiers of building materials engineering" by the Society of Materials Engineering for Resources in Japan in 2009 and "for distinguished service and leadership in the field of polymers in concrete" in 2004, when he received Owen Nutt Award. He is author and co-author of numerous scientific and technical papers, as well as many research project reports and 38 patents.

e-mail: I.czarnecki@itb.pl

Dionys Van Gemert, dr. ir., Professor Emeritus of building materials science and renovation of constructions at the Department of Civil Engineering of KU Leuven, Belgium. He was Head of the Building Materials and Construction Techniques Division and Head of the Reyntjens Laboratory for Materials Testing (1991-2008). His research concerns repairing and strengthening of constructions, deterioration and protection of building materials, and concrete polymer composites. He was President of International Congress on Polymers in Concrete (2001-2007) and President of WTA-International, Wissenschaftlich-Technische Arbeitsgemeinschaft für Bauwerkserhaltung und Denkmalpflege (1997-2001). He is Chairman of Triconsult n.v., spin-off of K.U.Leuven. He received the Owen Nutt award for outstanding achievements in polymers in concrete (2007). Author and coauthor of numerous journal and congress papers.

e-mail: dionys.vangemert@kuleuven.be 